\section{Public disclosure of health care-associated infections in Australia: quality improvement or parody?}

To THE EDITOR: National disclosure of health care-associated infections has recently been facilitated by the launch of the MyHospitals website by the Australian Institute of Health and Welfare (http://www.myhospitals. gov.au). As high rates of Staphylococcus aureus bacteraemia (SAB) have been reported at our tertiary health care facility, ${ }^{1}$ we wish to outline the pitfalls and potential misrepresentation of generic health care infection surveillance data when used for comparison of dissimilar health care services within a jurisdiction and in the public arena.

First, a robust surveillance strategy must apply risk stratification to ensure that disparate patient subgroups are adequately compared. ${ }^{2}$ In the case of $\mathrm{SAB}$, an important contributing risk factor is the presence of an indwelling venous catheter. If frequent or prolonged catheterisation is required, as in patients requiring total parenteral nutrition, haemodialysis or chemotherapy, this must be reported in tandem with infection rates. We note no such consideration in the recent MyHospitals report.

Second, if a target rate is applied to surveillance data, we expect this to be valid for all reported patient populations. In the case of $\mathrm{SAB}$, the National Healthcare Agreement has stipulated a threshold of 2 per 10000 occupied bed days for acute care public hospitals. ${ }^{3}$ This target has not been evaluated in the private sector or in non-acute patient groups, and it has not been considered for distinct application to specialised populations such as immunocompromised patient populations.

We agree that measures to prevent and minimise the risk of $\mathrm{SAB}$ are important and necessary for all health care facilities. However, we do not believe that tenuous target rates for SAB should be applied to unadjusted data obtained from high-risk immunocompromised patient populations. Others have also cautioned against such comparison. ${ }^{4}$ To date, no studies have shown a reduction in health care-associated infections as a direct result of public reporting. ${ }^{5}$ Further, we believe that the public disclosure of data on the MyHospitals website is misleading for the general public. We therefore call for discussion with all stakeholders about the development of appropriate risk indexing for specialised patient populations, before analysis or interpretation of data related to health care-associated infections is attempted.

\section{Leon J Worth Infectious Diseases Physician \\ Karin A Thursky Infectious Diseases Physician \\ Monica A Slavin Head}

Department of Infectious Diseases and Infection Control, Peter MacCallum Cancer Centre, Melbourne, VIC.

leon.worth@petermac.org

Competing interests: No relevant disclosures.

doi: 10.5694/mjal2.10466

1 Australian Institute of Health and Welfare. MyHospitals [website]. http:// www.myhospitals.gov.au/hospital/petermaccallum-cancer-institute/safety-and-quality/ (accessed Jan 2012).

2 McKibben L, Horan T, Tokars Jl, et al; Heathcare Infection Control Practices Advisory Committee. Guidance on public reporting of healthcareassociated infections: recommendations of the Healthcare Infection Control Practices Advisory Committee. Am J Infect Control 2005; 33: 217-226.

3 Council of Australian Governments (COAG). National healthcare agreement, 2011. http:// www.coag.gov.au/docs/national_healthcare_ agreement_2011.pdf (accessed Jan 2012).

4 Morton AP, Clements AC, Doidge SR, et al. Surveillance of healthcare-acquired infections in Queensland, Australia: data and lessons from the first 5 years. Infect Control Hosp Epidemiol 2008; 29: 695-701.

5 Mckibben L, Fowler G, Horan T, Brennan PJ. Ensuring rational public reporting systems for health care-associated infections: systematic literature review and evaluation recommendations. Am J Infect Control 2006; 34: 142-149. the public

disclosure of data

on the

MyHospitals

website is

misleading for the

general public

Worth et al 